\title{
Model Parameter Uncertainty Analysis for an Annual Field-Scale P Loss Model
}

Carl H. Bolster ${ }^{\mathrm{a},}{ }^{*}$, Peter A. Vadas ${ }^{\mathrm{b}}$, and Debbie Boykin ${ }^{\mathrm{c}}$

${ }^{a}$ Food Animal Environmental Systems Research Unit, USDA-ARS, Bowling Green, KY 42104, United States

${ }^{\mathrm{b}}$ Dairy Forage Research Center, USDA-ARS, Madison, WI 53706, United States

${ }^{\mathrm{c}}$ USDA-ARS, Stoneville, MS 38776, United States

* Corresponding author.

E-mail address: carl.bolster@ars.usda.gov (C.H. Bolster).

Keywords:

Annual P Loss Estimator model (APLE)

Model uncertainty

Confidence intervals

Prediction intervals

Phosphorus Modeling

Abbreviations: AP, active P; APLE, Annual P Loss Estimator; CI, confidence interval; LP, labile P; MCS, Monte Carlo simulations; PI, prediction interval; STP, soil test P. 


\section{SUMMARY}

Phosphorous $(\mathrm{P})$ fate and transport models are important tools for developing and evaluating conservation practices aimed at reducing P losses from agricultural fields. Because all models are simplifications of complex systems, there will exist an inherent amount of uncertainty associated with their predictions. It is therefore important that efforts be directed at identifying, quantifying, and communicating the different sources of model uncertainties. In this study, we conducted an uncertainty analysis with the Annual P Loss Estimator (APLE) model. Our analysis included calculating parameter uncertainties and confidence and prediction intervals for five internal regression equations in APLE. We also estimated uncertainties of the model input variables based on values reported in the literature. We then predicted P loss for a suite of fields under different management and climatic conditions while accounting for uncertainties in the model parameters and inputs and compared the relative contributions of these two sources of uncertainty to the overall uncertainty associated with predictions of P loss. Both the overall magnitude of the prediction uncertainties and the relative contributions of the two sources of uncertainty varied depending on management practices and field characteristics. This was due to differences in the number of model input variables and the uncertainties in the regression equations associated with each P loss pathway. Inspection of the uncertainties in the five regression equations brought attention to a previously unrecognized limitation with the equation used to partition surface-applied fertilizer P between leaching and runoff losses. As a result, an alternate equation was identified that provided similar predictions with much less uncertainty. Our results demonstrate how a thorough uncertainty and model residual analysis can be used to identify limitations with a model. Such insight can then be used to guide future data collection and model development and evaluation efforts. 


\section{Introduction}

The translocation of phosphorus $(\mathrm{P})$ from the landscape to surface waters via runoff, erosion, and/or subsurface leaching can lead to water quality deterioration of P-sensitive water bodies. The degradation of water quality resulting from $\mathrm{P}$ loading from diffuse sources is a global concern (Kleinman et al., 2015; Sharpley et al., 2015) with such notable examples as the Baltic Sea, Chesapeake Bay, Florida Everglades, Mississippi River, and Yangtze River (Boesch et al., 2006; Dai et al., 2011; Dale et al., 2010; Executive Order 13508, 2009; HELCOM, 2011;

Richardson et al., 2007). In many areas, agriculture is a significant contributor of P loading to Psensitive waters. To mitigate the effects of agricultural activities on water quality, decades of research has been devoted to better understanding the processes controlling $\mathrm{P}$ movement through the landscape and in developing conservation practices to minimize P losses (Radcliffe and Cabrera, 2007). Given the costs and long-term commitments associated with field-scale experiments, emphasis has also been placed on using field-scale models to test different management strategies on reducing $\mathrm{P}$ loss from agricultural fields. Model simulations have also been used to assess the effectiveness of various conservation practices at the watershed scale (USDA-NRCS, 2013). To corroborate the findings of any model, however, will require comparing model predictions with long-term monitoring data.

While model predictions of $\mathrm{P}$ fate and transport can provide useful information to researchers, land owners, regulatory agencies, and other stakeholders, uncertainties exist with all model predictions, regardless of how complex or "physically-based" a model may be. Several sources of uncertainty exist that are inherent to all P loss models (Beck, 1987; Beven et al., 2007; Gupta et al., 2012). These include model structure errors/inadequacies that result when approximating complex physical phenomena with simplified mathematical models. These approximations result 
from our incomplete knowledge of the system, as well as practical limitations of including all processes and associated parameters into the model. Moreover, errors may be introduced by the numerical methods employed for solving the model equations and how the model is discretized in time and space. In addition, there is an inherent amount of randomness within natural systems (both temporally and spatially), much of which is not adequately, or cannot reasonably be, captured by models. Measurement errors in the input variables that are required to run the model such as precipitation, evapotranspiration, soil test $\mathrm{P}, \mathrm{P}$ application rates, and initial and boundary conditions will also affect the accuracy of the model predictions. Moreover, there may be errors resulting from using unrepresentative values for these input variables; for instance, the use of measured soil test P (STP) at a point to describe spatially variable STP over a large area. Errors associated with the model parameters will also affect the reliability of the model predictions. The magnitude of the errors introduced from these different sources will depend on the validity of the model assumptions, the complexity of the model, the quality of the input data, and on how well the various model parameters have been estimated. Because these errors are often interrelated, it is difficult to isolate and obtain good estimates of their magnitude, particularly errors associated with model structure (Gupta et al., 2012; Yen et al., 2014). Further complicating matters is that multiple models and parameter sets may describe a data set equally well (Beven, 2006a). Nevertheless, efforts should be taken to obtain reasonable estimates of model uncertainties (National Research Council, 2007; USEPA, 2009). These uncertainties may be estimated by model uncertainty analysis, values reported in the literature, and/or expert assessment (Uusitalo et al., 2015).

The impact of model parameter uncertainty on predictions of $\mathrm{P}$ loss is arguably the most common type of uncertainty analysis conducted with P loss models (Barlund and Tattari, 2001; 
Beven et al., 2007; Dean et al., 2009; Krueger et al., 2009; McFarland and Hauck, 2001; Smith and Wheater, 2004; Veith et al., 2010; Zhang and Haan, 1996). Model parameters are those constants incorporated into the model equations for making calculations from input data. Values for model parameters are often estimated by adjusting (i.e. calibrating) their values (either manually or by an automated computer algorithm) until the differences between modeled and observed data are minimized. A commonly used method in the hydrological sciences for model calibration is least-squares regression, where values of the model parameters are chosen that minimize the sum of the squared differences between model predictions and observations. Uncertainties in the model parameters can be estimated from the resulting parameter variancecovariance matrix provided that the assumptions of least-squares regression are valid or not too badly violated (Seber and Wild, 2003; Draper and Smith, 1998; Helsel and Hirsch, 2002). Potential sources of errors in model parameters estimated by calibration include: using incorrect calibration performance measures (i.e. optimization targets); using inaccurate, incomplete, or unrepresentative data sets during model calibration; and ignoring uncertainties in the calibration data (Bolster and Tellinghuisen, 2010; Haan, 2002; Sorooshian and Gupta, 1995).

We recently conducted an analysis investigating the effects of model input error on prediction uncertainties of P loss at the field scale using the Annual P Loss Estimator (APLE) model (Bolster and Vadas, 2013), an empirically-based spreadsheet model developed to describe annual, field-scale $\mathrm{P}$ loss when surface runoff is the dominant $\mathrm{P}$ loss pathway (Vadas et al., 2009). In this study, we extend our analysis by evaluating the effects of model parameter uncertainties on predictions of P loss for APLE. The specific objectives of this study were to estimate the model parameter uncertainty associated with five internal regression equations used in APLE and to evaluate how the parameter uncertainties affect model prediction uncertainties. 
We estimate the parameter uncertainties associated with the regression equations used to estimate total soil $\mathrm{P}$ from measurements of soil clay content, organic matter, and labile $\mathrm{P}$; the $\mathrm{P}$ enrichment ratio calculated from erosion rates; concentration of $\mathrm{P}$ in runoff calculated from labile soil $\mathrm{P}$; and the partitioning of $\mathrm{P}$ between runoff and infiltration for applied manures and fertilizers based on runoff ratio. Our analysis included calculating parameter uncertainties and 95\% confidence and prediction intervals for the regression equations. We then calculated predictions of P loss using the APLE model while including uncertainties in model parameters and inputs and compared the relative magnitude of these sources of uncertainty to the overall uncertainty associated with predictions of P loss. Results from this study highlight the importance of including reasonable estimates of model parameter uncertainties when using models to predict $\mathrm{P}$ loss. Our results also demonstrate how the estimation of model parameter uncertainty can be used to identify model limitations.

\section{Methodology}

\subsection{Annual P Loss Estimator (APLE) Model}

The APLE model calculates annual total P loss in surface runoff from agricultural fields as (Vadas et al., 2009):

$\mathrm{P}_{\text {tot }}=\mathrm{P}_{\text {sed }}+\mathrm{DP}_{\text {soil }}+\mathrm{DP}_{\text {man }}+\mathrm{DP}_{\text {fert }}$

where $\mathrm{P}_{\text {tot }}$ is the total annual $\mathrm{P}$ loss from surface runoff $\left(\mathrm{kg} \mathrm{ha}^{-1}\right), \mathrm{P}_{\text {sed }}$ is annual sediment $\mathrm{P}$ loss

from eroded soil $\left(\mathrm{kg} \mathrm{ha}^{-1}\right), \mathrm{DP}_{\text {soil }}$ is annual dissolved $\mathrm{P}$ loss in runoff from soil $\left(\mathrm{kg} \mathrm{ha}^{-1}\right), \mathrm{DP}_{\operatorname{man}}$ is annual dissolved $\mathrm{P}$ loss in runoff from applied manure $\left(\mathrm{kg} \mathrm{ha}^{-1}\right)$, and $\mathrm{DP}_{\text {fert }}$ is annual dissolved $\mathrm{P}$ 
loss in runoff from applied fertilizer $\left(\mathrm{kg} \mathrm{ha}^{-1}\right)$. Each component in Eq. (1) includes one or more terms obtained by regression as detailed below (Vadas et al., 2009).

The component estimating particulate $\mathrm{P}$ loss is calculated as:

$\mathrm{P}_{\mathrm{sed}}=\mathrm{SED} \cdot \mathrm{PER} \cdot \mathrm{TP} \cdot 10^{-6}$

where TP is total soil $\mathrm{P}\left(\mathrm{mg} \mathrm{kg}^{-1}\right), \mathrm{SED}$ is the annual erosion rate $\left(\mathrm{kg} \mathrm{ha}^{-1}\right), \mathrm{PER}$ is the $\mathrm{P}$ enrichment rate that accounts for the preferential movement of fine soil particles enriched in $\mathrm{P}$, and $10^{-6}$ is a unit conversion factor. The $\mathrm{P}$ enrichment ratio is calculated as:

$\mathrm{PER}=\mathrm{C}_{1} \cdot \mathrm{SED}_{2}^{\mathrm{C}}$

where $\mathrm{C}_{1}$ and $\mathrm{C}_{2}$ are regression coefficients. The model is coded so that PER has a minimum value of 1 .

Total soil $\mathrm{P}$ is determined by summing four simulated $\mathrm{P}$ pools: organic (OP), labile (LP), active (OP), and stable (SP). The organic P pool (OP) is calculated as:

$\mathrm{OP}=10^{4} \cdot \mathrm{SOC} /(\mathrm{NP} \cdot \mathrm{CN})$

where $10^{4}$ is a unit conversion factor, SOC is percent soil organic carbon (assumed to be equal to $58 \%$ of soil organic matter), NP is the nitrogen to phosphorus ratio in the soil organic matter (assumed to be 8), and $\mathrm{CN}$ is the carbon to nitrogen ratio of the soil organic matter (assumed to be 14). The active (AP) and stable P (SP) pools are determined by (Jones et al., 1984):

$$
\begin{aligned}
& \mathrm{AP}=\mathrm{LP} \cdot(1-\mathrm{PAI}) / \mathrm{PAI} \\
& \mathrm{SP}=4 \cdot \mathrm{AP}
\end{aligned}
$$


where LP is labile $\mathrm{P}$ and defined as being equal to half of Mehlich-3 equivalent $\mathrm{P}$ (Vadas et al., 2009), PAI is the phosphorus availability index representing how much $\mathrm{P}$ added to soil remains labile following chemical equilibration. In APLE, PAI is determined from percent soil clay (Clay), LP, and SOC using the following empirical relationship (Vadas and White, 2010):

$\mathrm{PAI}=-\mathrm{C}_{3} \cdot \ln ($ Clay $)+\mathrm{C}_{4} \cdot \mathrm{LP}-\mathrm{C}_{5} \cdot \mathrm{SOC}+\mathrm{C}_{6}$

where $\mathrm{C}_{3}$ through $\mathrm{C}_{6}$ are regression coefficients.

The component for describing dissolved $\mathrm{P}$ loss from soil is formulated as:

$\mathrm{DP}_{\text {soil }}=\mathrm{DPC} \cdot \mathrm{RO} \cdot 0.1$

$\mathrm{DPC}=\mathrm{C}_{7} \cdot \mathrm{LP}$

where DPC is the dissolved P concentration in runoff $\left(\mathrm{mg} \mathrm{L}^{-1}\right), \mathrm{C}_{7}$ is the $\mathrm{P}$ extraction coefficient $\left(\mathrm{kg} \mathrm{L}^{-1}\right)$ obtained by regression, $\mathrm{RO}$ is annual runoff $(\mathrm{cm})$, and 0.1 is a unit conversion factor (Vadas et al., 2005).

The component for describing dissolved P loss from applied inorganic fertilizers is calculated as:

$\mathrm{DP}_{\text {fert }}=\mathrm{P}_{\mathrm{F}} \cdot(\mathrm{RO} / \mathrm{PT}) \cdot \mathrm{PD}_{\mathrm{F}}$

$\mathrm{PD}_{\mathrm{F}}=\mathrm{C}_{8} \cdot \exp \left[\mathrm{C}_{9} \cdot(\mathrm{RO} / \mathrm{PT})\right]$

where $\mathrm{P}_{\mathrm{F}}$ is the amount of fertilizer P remaining on the surface following application $\left(\mathrm{kg} \mathrm{ha}^{-1}\right)$, $\mathrm{PT}$ is annual precipitation $(\mathrm{cm}), \mathrm{PD}_{\mathrm{F}}$ is an empirical $\mathrm{P}$ distribution factor that partitions $\mathrm{P}$ between runoff and infiltration (Vadas et al., 2008), and $\mathrm{C}_{8}$ and $\mathrm{C}_{9}$ are regression coefficients. 
The component for calculating dissolved P loss from applied manures is similarly formulated:

$\mathrm{DP}_{\operatorname{man}}=\mathrm{MAN} \cdot \mathrm{TP}_{\mathrm{M}} \cdot[\mathrm{WEP}+\mathrm{MRL}(1-\mathrm{WEP})] \cdot(\mathrm{RO} / \mathrm{PT}) \cdot \mathrm{PD}_{\mathrm{M}}$

$\mathrm{PD}_{\mathrm{M}}=(\mathrm{RO} / \mathrm{PT})^{\mathrm{C} 10}$

where MAN is the total amount of manure remaining on the surface following incorporation $(\mathrm{kg}$

$\left.\mathrm{ha}^{-1}\right), \mathrm{TP}_{\mathrm{M}}$ is the $\mathrm{P}$ fraction of the manure, WEP is the manure $\mathrm{P}$ fraction that is water-extractable, MRL is the fraction of non-WEP mineralized to WEP over the course of a year, $\mathrm{PD}_{\mathrm{M}}$ is an empirical P distribution factor that partitions P between runoff and infiltration (Vadas et al., 2004), and $\mathrm{C}_{10}$ is a regression coefficient.

\subsection{Calculating Regression Parameter and Equation Uncertainties}

The objectives of this research were to estimate the uncertainties associated with each of the five regression equations used for calculating PER, PAI, DPC, $\mathrm{PD}_{\mathrm{F}}$, and $\mathrm{PD}_{\mathrm{M}}$ and to evaluate how these uncertainties affect APLE predictions of P loss. Best-fit values and estimates of the uncertainties for each of the 10 coefficients listed above (i.e. $\mathrm{C}_{1}$ through $\mathrm{C}_{10}$ ) were obtained using least-squares regression where the best-fit values of the model parameters were chosen that minimize the sum of the squared errors (SSE) between model predictions and observations:

$\mathrm{SSE}=\boldsymbol{e}^{T} \boldsymbol{\omega} \boldsymbol{e}$

where $\boldsymbol{e}$ is a vector of the differences in observed and model predicted values (termed model errors or fit residuals), $T$ signifies a transposed matrix, and $\omega$ is the full weight matrix (Seber and Wild, 2003); for uncorrelated errors a diagonal weight matrix replaces the full weight matrix in Eq. (14). For unweighted least-squares regression, the weight matrix is simply an identity matrix (Draper and Smith, 1998). When using unweighted data, greater emphasis is placed on fitting the 
larger values of the response variables at the expense of fitting the smaller values. This is appropriate when the uncertainty in the data (specifically the variance) is constant (i.e. homoscedastic). In most cases, however, the variance will increase with increasing values of the response variable. For heteroscedastic data (i.e. data with non-constant variance), the data should be weighted in such a way that reflects their uncertainty thereby giving greater emphasis on fitting the most accurate data. Ideally, the data should be weighted by the inverse of the variancecovariance matrix of the observation errors, resulting in minimum-variance estimates of the model parameters and reliable estimates of their uncertainties (Draper and Smith, 1998; Seber and Wild, 2003). In field studies, however, it is rare to have sufficient data to accurately quantify the data uncertainty, and this is certainly true of the data sets used in our analysis. When good estimates of the uncertainty are unknown, one commonly used approach is to assume that the variance of the error is proportional to the response variable (Hill and Tiedeman, 2007). In this study, we fit the data using both constant and proportional error and compared the best-fit model parameters and their uncertainties. For the weighted data we used a relative weighting scheme where $w=\mathrm{y}^{-2}$. To obtain unbiased estimates of the parameters, we weighted the data by the inverse of the predicted rather than observed values of the response variables (Anderman and Hill, 1999). This also allowed us to calculate a simple relationship for calculating uncertainties based on model predictions. Data used for fitting equations for PER, PAI, DPC, PD, and PD $_{M}$ are the same data used by Sharpley (2007), Vadas and White (2010), Vadas et al. (2005), Vadas et al. (2008), and Vadas et al. (2004), respectively. Data were fit with SAS 9.3 using PROC NLIN (SAS Institute Inc., 2011). 
The amount of variability in the observed data not captured by the regression equations was quantified by the mean absolute percent error (MAPE) of the log-transformed relative model errors:

$$
\mathrm{MAPE}=\operatorname{anti} \log \left[\frac{100}{n} \sum_{i=1}^{n} \log \left|\frac{e_{i}}{O_{i}}\right|\right]
$$

where $O_{i}$ is the $i^{\text {th }}$ observed value. We used log-transformed data because the model errors spanned several orders of magnitude in some of the regression models. Goodness of fit was quantified with the mean square error $(\mathrm{MSE}=\mathrm{SSE} / \mathrm{n})$ and the Nash-Sutcliffe model efficiency (NSE).

Uncertainties in the fitted regression coefficients were calculated from the variancecovariance matrix. Using this method, asymptotic parameter uncertainties are calculated by linearizing nonlinear equations using a first-order Taylor series expansion. Thus, uncertainties calculated with this method are only approximate for nonlinear equations, but are generally reliable if the equation is close-to-linear in the vicinity of the best-fit parameter values. For highly nonlinear equations, a more accurate method for estimating parameter uncertainties is to calculate joint confidence regions (Hill and Tiedeman, 2007; Vecchia and Cooley, 1987). To test the accuracy of the asymptotic method for estimating parameter uncertainties for the APLE equations, we initially compared confidence intervals for both the best-fit parameters and model predictions calculated by SAS with uncertainties calculated using joint confidence regions using the method of Vecchia and Cooley (1987) for the most nonlinear equation, $\mathrm{PD}_{\mathrm{F}}$. Differences between the two methods were minimal (data not shown) indicating that the use of the variance- 
covariance matrix for calculating uncertainties for the regression equations evaluated in our study was appropriate.

We calculated both confidence and prediction intervals associated with PER, PAI, DPC, PDF, and $\mathrm{PD}_{\mathrm{M}}$ for both unweighted $(w=1)$ and weighted $\left(w=\mathrm{y}_{\text {pred }}{ }^{-2}\right)$ data. Confidence intervals (CIs) quantify the uncertainty associated with the mean response of the dependent variable due to uncertainties in the fitted model parameters. Prediction intervals (PIs), on the other hand, quantify the uncertainty associated with the prediction of a single value of the dependent variable (Helsel and Hirsch, 2002). The prediction intervals incorporate not only the uncertainties in the model parameters but also the unexplained variability in the response variable and thus are generally much wider than confidence intervals. Confidence intervals for each equation were calculated as:

$C I=f(\beta) \pm \sqrt{M S E \cdot \frac{h_{i}}{w_{i}}} \cdot t\left(n-p, 1-\frac{\alpha}{2}\right)$

whereas the prediction intervals for each equation were calculated as:

$$
\begin{aligned}
& P I=f(\beta) \pm \sqrt{M S E \cdot\left(h_{i}+\frac{1}{w_{i}}\right)} \cdot t\left(n-p, 1-\frac{\alpha}{2}\right) \\
& h_{i}=w_{i} J X_{i}\left(X^{\prime} \omega X\right)^{-1} X_{i}^{\prime}
\end{aligned}
$$

where $f(\beta)$ is the value of the best-fit model, $\beta$ is a vector containing the best-fit parameter values, $w_{i}$ is the weight for the $i^{\text {th }}$ observation, $n$ is the number of observations, $p$ is the number of fitting parameters, $\alpha$ is the significance level, $t$ is the student t-statistic, $h_{i}$ is the hat matrix, and $X$ 
is the design matrix for linear models and the Jacobian matrix for nonlinear models. Confidence and prediction intervals were calculated using SAS 9.3 (SAS Institute Inc., 2011).

Regression equations were developed relating the standard deviation in the $95 \%$ PIs to the predicted values of PER, PAI, DPC, $\mathrm{PD}_{\mathrm{F}}$, and $\mathrm{PD}_{\mathrm{M}}$. This relationship was then used to calculate the $95 \%$ PIs for each regression equation for the observed P loss data set. Standard deviations for the 95\% PIs for PER, PAI, DPC, $\mathrm{PD}_{\mathrm{F}}$, and $\mathrm{PD}_{\mathrm{M}}$ were calculated by dividing the PIs obtained during the regression by two times the t-statistic for the appropriate degrees of freedom.

\subsection{Calculating Uncertainties for Model-Predicted P Loss}

Model predictions of $\mathrm{P}$ loss and their uncertainties were calculated for a range of conditions using published land management and P loss data compiled by Vadas et al. (2009) to evaluate the APLE model. We chose a subset of these data and grouped each field (FG) based on P source and presence/absence of measurable erosion as follows (Tables 1 and 2): FG I) no P applied (Jones et al., 1984), FG II) P applied as inorganic fertilizer with measurable erosion (McDowell and McGregor, 1980; Soileau et al., 1994), FG III) P applied as manure to fields without measureable erosion (Edwards et al., 1996), FG IV) P applied as manure to fields with measureable erosion (Harmel et al., 2004), FG V) P applied both as fertilizer and manure to fields without measureable erosion (Owens and Shipitalo, 2006), and FG VI) P applied both as fertilizer and manure to fields with measurable erosion (Thoma et al., 2005; Westerman et al., 1987; Young and Holt, 1977). Uncertainties in predictions of field-scale P loss were calculated by incorporating uncertainties in PER, PAI, DPC, $\mathrm{PD}_{\mathrm{F}}$, and $\mathrm{PD}_{\mathrm{M}}$ using both the $95 \% \mathrm{CI}$ and $\mathrm{PI}$ for each of the regression equations. We also calculated uncertainties in the model input variables (SED, $\mathrm{P}_{\mathrm{F}}, \mathrm{MAN}, \mathrm{TP}_{\mathrm{M}}$, WEP, RO, PT, Clay, $\mathrm{LP}$, and SOC) to compare the relative magnitude of the uncertainties associated with the regression equations to errors associated with 
the model input variables. Specifically, uncertainties in predicted P loss were calculated for the following eight error treatments:

(1) Error in the regression equations calculated from the $95 \%$ CIs for each of the five regression equations and error-free model inputs.

(2) Error-free regression equations with uncertainties of $\pm 5 \%$ in the model input variables.

(3) Error-free regression equations with uncertainties of $\pm 15 \%$ in the model input variables.

(4) Error in the regression equations calculated from the $95 \%$ CIs and $\pm 5 \%$ error in the model input variables.

(5) Error in the regression equations calculated from the $95 \%$ CIs and $\pm 15 \%$ error in the model input variables.

(6) Error in the regression equations calculated from the 95\% PIs and error-free model inputs.

(7) Error in the regression equations calculated from the $95 \%$ PIs and $\pm 5 \%$ error in the model input variables.

(8) Error in the regression equations calculated from the $95 \%$ PIs and $\pm 15 \%$ error in the model input variables.

For the model input variables, we used a symmetrical triangular distribution of errors with a range of \pm 5 or $15 \%$ of the mean value (Bolster and Vadas, 2013; Harmel et al., 2006; Harmel et al., 2009). The standard deviation of the symmetrical triangular distribution for each of the model input variables was calculated from the mode and minimum value of the distribution by:

$\sigma=\frac{\text { mode }- \text { minimum }}{\sqrt{6}}$ 
Model prediction uncertainties were calculated using Monte Carlo simulations where values for each variable were selected randomly from the appropriate distribution (Gaussian for the regression variables, triangular for the remaining input variables), the model was run, and the output stored. This process was repeated 10,000 times for each combination of model input variables representing a range in land management practices as shown in Table 1. Lower limits of the $95 \%$ CIs were calculated by determining the values from the model output distribution at which $97.5 \%$ of the values fell above and $2.5 \%$ of the values fell below. Upper limits of the $95 \%$ CIs were determined similarly as the value at which $2.5 \%$ of the values fell above and $97.5 \%$ of the values fell below. The relative magnitude of each of the uncertainties was calculated by dividing the interval by the predicted P-loss values.

\section{Results and Discussion}

\subsection{Uncertainties in regression equations}

Statistically significant fits were observed for all five of the regression equations tested $(\mathrm{p}<$ 0.001) with Nash-Sutcliffe efficiency (NSE) values exceeding 0.65 for all equations except PAI (Table 3) indicating good overall fits to the observed data. A large amount of scatter, however, was also observed (Figs. 1-5) indicating that a substantial portion of the variability in the observed data was not captured by these equations, particularly for PAI (Fig. 2). Mean absolute percent errors (MAPE) were lowest for PER and $\mathrm{PD}_{\mathrm{M}}$ with values of $11 \%$ for both weighting methods and highest for PAI, DPC, and $\mathrm{PD}_{\mathrm{F}}$ with values ranging from 24 to $35 \%$ depending on weighting (Table 3). The differences in the best-fit parameter values obtained using the two weighting methods were $11 \%$ or less for all regression coefficients except for $\mathrm{C}_{5}(37 \%)$ in the 
PAI equation (Table 4). As a result, differences in model fits between the two weighting methods were indistinguishable for all equations except PAI (data not shown).

\section{Figures 1 - 5}

Estimates of the parameter standard errors for PER, DPC, and $\mathrm{PD}_{\mathrm{M}}$ were $6 \%$ or less of the best-fit parameter estimates, regardless of weighting method. Parameter standard errors were much greater for the $\mathrm{PAI}$ and $\mathrm{PD}_{\mathrm{F}}$ regression equations ranging from 6 to $16 \%$ of the fitted parameter values for PAI and from 10 to $26 \%$ for $\mathrm{PD}_{\mathrm{F}}$ (Table 4). In general, differences in the magnitude of the parameter standard errors in relation to the fitted parameter values were minor between weighting methods. The greatest difference was with $\mathrm{C}_{4}$ of the PAI equation, where the coefficient of variation of the parameter standard error was reduced from 15 to $8.4 \%$ when using weighted data. The uncertainty associated with the mean response of the five regression equations due to uncertainties in the best-fit model parameters varied considerably depending on the equation (Figs. 1-5). For instance, the $95 \%$ confidence intervals (CIs) were less than $\pm 15 \%$ of the model-predicted values for PER, DPC, and $\mathrm{PD}_{\mathrm{M}}$ for both the unweighted and weighted data (Table 5); values similar in magnitude to the uncertainties we estimated ( \pm 5 to $20 \%$ ) for the APLE input variables (Bolster and Vadas, 2013). For PAI and $\mathrm{PD}_{\mathrm{F}}$, however, the CIs were noticeably wider (Figs. 2 and 4). Values for PAI ranged from \pm 4 to $40 \%$ and 4 to $22 \%$ for unweighted and weighted data, respectively. For $\mathrm{PD}_{\mathrm{F}}$, the CIs ranged from \pm 11 to $57 \%$ for the unweighted data and \pm 23 to $57 \%$ for the weighted data.

The relatively large uncertainties in the regression coefficients for $\mathrm{PD}_{\mathrm{F}}$ compared with those of $\mathrm{PD}_{\mathrm{M}}$ warrant closer inspection of this equation. The large uncertainties in $\mathrm{PD}_{\mathrm{F}}$ result in part from calibrating on a small dataset (ten-fold fewer data points than $\mathrm{PD}_{\mathrm{M}}$ ); thus, one way to 
reduce the uncertainty associated with $\mathrm{PD}_{\mathrm{F}}$ is to increase the number of high-quality observations used for calibration, though we are unaware of any additional data available for such analysis. The primary reason for the large uncertainties, however, is that the two fitted coefficients for $\mathrm{PD}_{\mathrm{F}}$ are highly correlated ( $r$ value of -0.93 or -0.97 depending on weighting). This resulted in the equation being relatively insensitive to perturbations in the parameter values, thereby leading to large parameter uncertainties. Replacing this equation with one that is more sensitive to changes in the parameter values (i.e. larger values of the Jacobian or design matrix) will result in smaller uncertainties, provided the equation produces similar fits to the data. For example, when we removed the two highest values of runoff ratio from our analysis (representing unrealistically high values for annual runoff ratio for most fields), and refit the data using both a one-parameter linear and the two-parameter exponential equation, we obtained nearly as good a fit to the data using the linear equation as we did with the original two-parameter exponential $\mathrm{PD}_{\mathrm{F}}$ equation (Fig. 6). This was evidenced by MSE, MAPE, and NSE values of $0.0038,25 \%$, and 0.52 for the linear equation and $0.0037,26 \%$, and 0.55 for the nonlinear equation. The relative parameter uncertainty for the linear equation, however, was only $7.3 \%$ compared with 22 and $33 \%$ for the nonlinear equation resulting in $\mathrm{CI}$ widths of $\pm 16 \%$ for the linear equation and $\pm 16-48 \%$ for the nonlinear equation. While additional data and analyses are needed to determine the equation that produces the most accurate estimates of $\mathrm{PD}_{\mathrm{F}}$ with the least amount of uncertainty, this example shows how calculating and evaluating parameter uncertainties can be useful for critically evaluating model equations.

\section{Figure 6}

As expected, the calculated $95 \%$ prediction intervals (PIs) were much wider than the CIs for each equation (Figs. 1B to 5B; Table 5). Where the CI for DPC was $\pm 2.7 \%$ of the model 
predicted value for the unweighted data, the PI for this equation ranged from $\pm 15-3400 \%$ of the mean value, representing an increase by a factor of 5.5 to more than 1200 . The least amount of difference between the CIs and PIs was for PAI, where the PI was less than 6 times wider than the CI for all data points. The 95\% PIs are much wider than the CIs because they account for variation in the dependent variable not accounted for by uncertainties in the best-fit model parameters and thus reflect the large amount of variability in the observed data not captured by these equations. This resulted in the 95\% PIs encompassing physically unrealistic values for PAI, $\mathrm{DPC}$, and $\mathrm{PD}_{\mathrm{F}}$ (either negative values or values exceeding 1 for $\mathrm{PD}_{\mathrm{F}}$ ) and was most pronounced for $\mathrm{PD}_{\mathrm{F}}$ and DPC using proportional error weighting (Figs. 3B and 4B). Some of this unexplained variability is likely a result of the equations being calibrated on data collected over a wide range of conditions. Developing more region- or watershed-specific equations for estimating these variables may result in better model fits and smaller uncertainties but will require a significant investment of resources to collect and analyze the needed data. Moreover, these empirically-based equations for estimating annual-based P loss were derived from eventbased data and were intentionally developed using easily accessible data as inputs (Vadas et al., 2004; Vadas et al., 2005; Vadas et al., 2008; Vadas and White, 2010). As a result, these equations do not capture all of the processes controlling P loss at the field scale. For instance, the equation for estimating PAI does not include important soil chemical properties (i.e. $\mathrm{Fe}, \mathrm{Al}, \mathrm{Ca}$, content and $\mathrm{pH}$ ) known to affect soil P sorption capacity. While this highlights a potential improvement for future versions of APLE, it does not mean the model is conceptually or computationally wrong, especially since it has been well tested for simulating changes in soil P over time. 
To reduce the uncertainties in the regression equations will require developing equations that better describe the observed variability in PER, DPC, $\mathrm{PD}_{\mathrm{M}}, \mathrm{PD}_{\mathrm{F}}$, and PAI. There are, however, trade-offs with developing more complex equations. For one, this will require the identification of additional soil properties that improve the predictive capability of these equations; properties which may not currently be measured in routine soil analyses or are readily available in databases. As the complexity of an equation increases, the number of input variables and model parameters to be estimated also increases, which in turn can lead to greater uncertainties. While a model with too few parameters may not entirely capture important processes, too many parameters may result in an over-parameterized model lacking good predictive power. Therefore, decisions must be made as to what constitutes an acceptable model given the particular application in which the model is to be used (Jakeman et al., 2006). With APLE, the intention was to develop a user-friendly model that minimized inputs, data requirements, time and skill required to run, and is applicable to many regions yet still provide reasonably accurate estimates of P loss at the field scale. What constitutes an acceptable model should be based on scientific criteriaas well as take into account socio-economic factors with stakeholder participation (Pappenberger and Beven, 2006; Refsgaard et al., 2007; Reichert and Borsuk, 2005; Voinov and Bousquet, 2010).

\subsection{Uncertainties in model predictions}

Using the 95\% CIs calculated for the five regression equations, we calculated the uncertainties associated with APLE predictions of P loss using as model inputs the reported values from the field-scale studies included in our compiled data set (Table 1). The 95\% CIs for APLE predictions of P loss ranged from 6 to $20 \%$ of the model-predicted values for model input

errors of $\pm 5 \%$ and 14 to $24 \%$ for model input errors of $\pm 15 \%$ (Fig. 7). The relative magnitude of 
the two sources of error (model parameter and model input) on the uncertainties in modelpredicted $\mathrm{P}$ loss varied depending on $\mathrm{P}$ management practices and erosion losses (Fig. 8). For instance, model parameter uncertainty was generally larger than the uncertainty resulting from \pm $5 \%$ error in the model inputs for fields with no P application (FG I), P applied as manure to fields without erosion (FG IV), and P applied both as fertilizer and manure to fields with erosion (FG VI). For these fields, including uncertainty with the model input variables did not noticeably increase model prediction uncertainties. Conversely, when both fertilizer and manure were applied to fields with no significant erosion (FG V), model input uncertainty contributed the majority of the uncertainty in the model predictions. Where P was applied as fertilizer (FG II) or manure (FG III) to fields with measurable erosion, the relative magnitude of the uncertainties from model parameters and model inputs varied between studies. When uncertainty in model inputs was increased to $\pm 15 \%$, the contribution of model input uncertainty to model-prediction uncertainty became, as expected, more significant. For FGs I and II, model input uncertainty exceeded model parameter uncertainty and for FGs IV and VI, model input uncertainties were similar in magnitude as model parameter uncertainties. For FG V, the contribution of model input uncertainty was even more pronounced when compared with model input uncertainties of \pm $5 \%$. With the exception of FGs II and V, uncertainties in both sources contributed to the overall model prediction uncertainty indicating the need to include both sources of error when calculating model prediction uncertainties for the APLE model.

\section{Figure 7}

When using the $95 \%$ PIs prediction intervals to calculate uncertainties in the regression equations, the uncertainties in APLE predictions of P loss ranged from 35 to $270 \%$ of the modelpredicted values for both weighting treatments (Fig. 8). In comparison, the magnitude of the 
model input uncertainties was negligible (data not shown). Whereas confidence intervals (CIs) quantify the amount of uncertainty associated with the regression parameters, prediction intervals (PIs) also account for the unexplained variability in the dependent variable along with the uncertainties in the regression parameters. Thus PIs should be used when comparing model predictions to individual observations of $\mathrm{P}$ loss (Helsel and Hirsch, 2002). Using the PIs from the five regression equations to calculate uncertainties of predictions of $\mathrm{P}$ loss resulted in such wide error bars as to make model predictions of individual observations of P loss of limited value. As noted earlier, to reduce the uncertainties associated with individual predictions of $\mathrm{P}$ loss will require reducing the uncertainties associated with the five internal regression equations used for calculating PER, DPC, $\mathrm{PD}_{\mathrm{M}}, \mathrm{PD}_{\mathrm{F}}$, and PAI.

\section{Figure 8}

\subsection{Analysis and limitations of uncertainty estimates}

In this study we used statistical inference methods - specifically, least-squares regression - to obtain the best-fit parameter values and estimates of their uncertainties for the five APLE regression equations. Therefore, the accuracy of the best-fit parameters and their uncertainties depends on whether the inherent assumptions behind least-squares regression are valid (or at least not too badly violated). These assumptions include constant (i.e. homoscedastic) and normally distributed errors, error-free independent variables, and that the "correct" model is fit to the data (Seber and Wild, 2003). For the five regression equations used in this study, the socalled independent variables were measured and thus contain some error. When errors in the independent variable are large, suboptimal estimates of the model parameters and their uncertainties may result when using traditional least-squares regression (Bolster and 
Tellinghuisen, 2010). While alternative regression methods do exist that account for errors in both the dependent and independent variables (Seber and Wild, 2003; Tellinghuisen and Bolster, 2009), we chose not to use any of these methods because good estimates of the uncertainties in the independent variables were not available.

The validity of the assumptions of homoscedastic and normally distributed errors cannot be checked directly but an indirect check can be made by analyzing the fit residuals (Helsel and Hirsch, 2002). If the distributions of residuals do not conform to these assumptions, then the data may be incorrectly weighted, the observation data are inaccurate, and/or the model is not appropriate for describing the observed data (Bevington and Robinson, 1992; Hill and Tiedeman, 2007; Tellinghuisen and Bolster, 2010). Inspection of the residual plots for the unweighted data (Supporting information, Figs. S1-S5) indicates that the residuals for the PER equation are normally distributed and $\mathrm{PD}_{\mathrm{M}}$ and $\mathrm{PD}_{\mathrm{F}}$ are close-to-normally distributed (Figs. S1-S3). The magnitude of the residuals for these equations does vary depending on their measured values suggesting some heteroscedasticity (Figs. S1-S3); however, lower variability in the residuals tended to coincide with regions of fewer data points and therefore we cannot state conclusively whether the data violate the constant variance assumption. For the PAI and DPC equations, residual plots indicate heteroscedastic and non-normally distributed residuals (Figs. S4 and S5). Using relative weighting did not result in the fit residuals better conforming to assumptions of least-squares regression (Figs. S6-S10). Given that the data used for this analysis were collected from multiple published studies, it is likely that the actual errors varied between studies and that our two assumed error distributions were oversimplifications of the actual errors in the data. Our two assumed error distributions, however, do represent a wide range in error structures and the fact that our fitted parameter values and their uncertainties were similar for the unweighted and 
weighted data suggest that incorrect weighting is unlikely the major reason that the distributions in some of our fit-residuals were not consistent with the assumptions of least-squares regression.

The primary reason for our fit-residuals not conforming to the expected distribution is most likely due to model structure errors/inadequacies. As mentioned previously, the empiricallybased equations developed for APLE are inherently limited in their ability to capture all of the physical processes controlling P loss at the field scale. While this suggests that these regression equations are imperfect, it does not mean that they are wrong for the purposes and conditions for which they were developed; indeed, any set of equations describing natural processes in the environment will be incomplete resulting in some model structure error. Therefore, prediction uncertainties calculated based only on uncertainties in the model inputs and parameters will underestimate the total uncertainty associated with the model. This is underscored by our observation that the prediction uncertainties for the APLE model are much larger when calculated from the PIs of the regression equations - which account for unexplained variability (i.e. model structure error) in the equations - than when calculated from the CIs - which only account for uncertainties in the regression coefficients.

While model structure errors potentially represent the largest source of uncertainty in environmental models - and will become more dominant as the model is applied to conditions different from those in which it was calibrated -only a limited number of studies have specifically addressed this source of error in model prediction uncertainty analyses (Beven et al., 2007; Gupta et al., 2012; Refsgaard et al., 2006; Refsgaard et al., 2007; Yen et al., 2014). The reasons for this include the difficulty (impossibility?) of disentangling model structure errors from other sources of error without making some strong assumptions about the magnitude of errors from other sources, the lack of quantitative metrics for assessing model structure 
inadequacies, and an agreed upon definition of what constitutes an adequate model structure (Gupta et al., 2012). Nevertheless, efforts should be directed at developing methodologies for estimating and incorporating model structure uncertainties into predictions of $\mathrm{P}$ movement through the landscape. One approach is to apply multiple models - ideally representing a range in plausible model structures (both perceptual and conceptual) - to the same data set and using the resulting ensemble of model outputs for estimating model prediction uncertainties (Beven and Binley, 1992; Bormann et al., 2009; Butts et al., 2004; Georgakakos et al., 2004; Gupta et al., 2012; Refsgaard et al., 2006; Refsgaard et al., 2007).

Given the ubiquity of model structural errors (or inadequacies), the difficulty of separating these errors from other sources of error in environmental models, and the likelihood that there exists multiple descriptions of reality (i.e. models) that will describe most data sets equally well, the use of traditional statistical inference methods for calculating uncertainties for environmental models has been questioned (Beven and Binley, 1992; Beven, 2002; Beven, 2006a; Beven, 2006b). As an alternative to statistical inference methods, Beven and Binley (1992) developed the Generalized Likelihood Uncertainty Estimation (GLUE) method. The GLUE method seeks to identify the model(s) and parameter sets that produce an acceptable fit to the data as defined by an informal likelihood measure and thus is not based on any assumptions regarding the modeling error structure. This method does, however, require a user-defined performance measure(s) and a subjective determination of what simulations are behavioral (i.e. acceptable) and non-behavioral. Examples of the GLUE method being applied to P loss models include studies by Dean et al. (2009), Krueger et al. (2009), and Beven et al. (2007). Future research should be directed at applying the GLUE method for estimating uncertainties with the APLE model and comparing these uncertainties with the uncertainties estimated in this study using least-squares regression 


\section{Conclusions}

In this study we conducted an uncertainty analysis for the APLE model focusing on uncertainties in the model parameters obtained by least-squares regression. Although our residual plots indicate that the assumptions of least-squares regression were not strictly valid for some of the regression equations, we do believe that our uncertainty estimates are reasonable and provide important insights regarding the magnitude of model input and parameter uncertainties for APLE and how the relative importance of these uncertainties varies depending on $\mathrm{P}$ source and erosion rate. We also demonstrate how a thorough uncertainty and model residual analysis can be used to indentify limitations with a model. Such insight can be used to guide future data collection and model development and evaluation efforts.

To be sure, incorporating a thorough uncertainty and residual analysis requires additional time, expertise, and in many cases additional data. Neglecting model uncertainties, however, implies a level of confidence in the model predictions that is simply not warranted and can lead to unrealistic expectations of the model's ability to predict future results; when the model inevitably fails to meet these expectations, the model may be unduly criticized. It is therefore imperative that strategies are developed and implemented for identifying, quantifying, incorporating, and reducing the sources and magnitude of a model's uncertainty (National Research Council, 2007; Pappenberger and Beven, 2006; USEPA, 2009). Care must be taken, however, when presenting model uncertainties and limitations to stakeholders, particularly when communicating modeling results to audiences that lack the technical expertise for properly

evaluating what the uncertainties and residuals represent (Janssen et al., 2005; Pappenberger and 
Beven, 2006). Nonetheless, reasonable estimates of model prediction uncertainties can provide model users and decision makers with a better picture of the probability of reaching desired goals following implementation of proposed changes in land use and management, thereby allowing decision makers to better allocate limited resources for conservation and mitigation efforts (Georgakakos et al., 2004).

\section{Acknowledgments}

We are grateful for the thoughtful comments provided by two anonymous reviewers. This research was part of USDA-ARS National Program 212: Soil and Air Research Program. The authors declare no competing financial interest. USDA is an equal opportunity provider and employer.

\section{Appendix A. Supplementary material}

Supplementary data associated with this article can be found, in the online version, at 


\section{Table 1}

Ranges in values of the salient model input variables used to evaluate model prediction uncertainties.

\begin{tabular}{|c|c|c|c|c|c|c|c|c|}
\hline $\begin{array}{l}\text { Date } \\
\text { Source }\end{array}$ & $\mathrm{n}$ & $\mathrm{FG}^{\mathrm{a}}$ & $\begin{array}{c}\text { Soil } \\
\text { test } \mathrm{P}^{\mathrm{b}}\end{array}$ & Runoff & Erosion & $\begin{array}{l}\text { Surface }^{c} \\
\text { manure P }\end{array}$ & $\begin{array}{c}\text { Surface }^{\mathrm{c}} \\
\text { fertilizer P }\end{array}$ & $\begin{array}{c}\text { Measured P } \\
\text { loss }\end{array}$ \\
\hline & & & $m g k^{-1}$ & $m m$ & $k g h a^{-1}$ & $k g h a^{-1}$ & $k g h a^{-1}$ & $k g h a^{-1}$ \\
\hline $\begin{array}{l}\text { Jones et al. } \\
\text { (1985) }\end{array}$ & 12 & I & 20 & $\begin{array}{l}5.2- \\
160\end{array}$ & $\begin{array}{l}100- \\
6700\end{array}$ & 0 & 0 & $0.1-4.2$ \\
\hline $\begin{array}{l}\text { McDowell } \\
\text { and Gregor }\end{array}$ & 5 & II & 20 & $\begin{array}{l}310- \\
880\end{array}$ & $\begin{array}{l}250- \\
29000\end{array}$ & 0 & $1.5-49$ & $2.7-18$ \\
\hline (1980) & & & & & & & & \\
\hline $\begin{array}{l}\text { Soileau et } \\
\text { al. (1994) }\end{array}$ & 6 & II & $39-83$ & $\begin{array}{l}86- \\
430\end{array}$ & $\begin{array}{l}910- \\
4300\end{array}$ & 0 & $5.8-25$ & $0.52-4.0$ \\
\hline $\begin{array}{l}\text { Edwards et } \\
\text { al. (1996) }\end{array}$ & 8 & III & 20 & $\begin{array}{l}53- \\
290\end{array}$ & 0 & $14-130$ & 0 & $0.8-5.2$ \\
\hline $\begin{array}{l}\text { Harmel et } \\
\text { al. (2004) }\end{array}$ & 14 & IV & $38-110$ & $\begin{array}{l}65- \\
350\end{array}$ & $\begin{array}{l}5.0- \\
12000\end{array}$ & $6.7-33$ & 0 & $0.4-11$ \\
\hline $\begin{array}{l}\text { Owens and } \\
\text { Shipitalo } \\
\text { (2006) }\end{array}$ & 28 & V & $28-80$ & $\begin{array}{l}8.8- \\
250\end{array}$ & 0 & $1.2-52$ & $40-150$ & $0.08-4.0$ \\
\hline $\begin{array}{l}\text { Thoma et } \\
\text { al. (2005) }\end{array}$ & 4 & VI & $35-58$ & $\begin{array}{c}2.0- \\
78\end{array}$ & $\begin{array}{l}73- \\
2800\end{array}$ & $1.1-7.1$ & $0-3.4$ & $0.1-4.0$ \\
\hline $\begin{array}{l}\text { Westerman } \\
\text { et al. } \\
\text { (1987) }\end{array}$ & 7 & VI & $60-400$ & $41-84$ & $\begin{array}{l}100- \\
300\end{array}$ & $0-300$ & $0-34$ & $0.4-4.8$ \\
\hline $\begin{array}{l}\text { Young and } \\
\text { Holt } \\
\text { (1977) }\end{array}$ & 3 & VI & 30 & $\begin{array}{l}38- \\
100\end{array}$ & $\begin{array}{c}10000- \\
20000\end{array}$ & $0-8.5$ & 16 & $8.1-14$ \\
\hline
\end{tabular}

${ }^{\mathrm{a}}$ Field grouping $(\mathrm{FG})$ 
${ }^{\mathrm{b}}$ Mehlich-3 P equivalent as estimated by Vadas et al. (2009).

${ }^{c}$ Calculated from estimates of incorporation rates by Vadas et al. (2009).

Table 2. Field groupings (FG) based on presence (+) or absence (-) of manure $P$, inorganic fertilizer $\mathbf{P}$, and erosion.

\begin{tabular}{|c|c|c|c|}
\hline FG & Erosion & P applied with manure & $\begin{array}{c}\text { P applied with inorganic } \\
\text { fertilizer }\end{array}$ \\
\hline I & + & - & - \\
\hline II & + & - & + \\
\hline III & - & + & - \\
\hline IV & + & + & - \\
\hline VI & - & + & + \\
\hline
\end{tabular}




\section{Table 3}

Mean square errors (MSE), mean absolute percent errors (MAPE), and Nash-Sutcliffe model efficiencies (NSE) for the best-fit model for the P enrichment ratio (PER), P availability index (PAI), dissolved P concentration from soil (DPC), P distribution factor for applied fertilizer $\left(\mathrm{PD}_{\mathrm{F}}\right)$, and $\mathrm{P}$ distribution factor for applied manure $\left(\mathrm{PD}_{\mathrm{M}}\right)$. Results shown for unweighted $(w=1)$ and weighted $\left(w=\mathrm{y}_{\text {pred }}{ }^{-2}\right)$ regression. All model fits are statistically significant at the $\mathrm{p}<0.0001$ level.

\begin{tabular}{lcccccc}
\hline Equation & MSE & MAPE & NSE & MSE & MAPE & NSE \\
\hline PER & 0.199 & $11 \%$ & 0.87 & 0.02 & $11 \%$ & 0.87 \\
PAI & 0.013 & $27 \%$ & 0.34 & 0.24 & $27 \%$ & 0.27 \\
DPC & 0.028 & $31 \%$ & 0.83 & 0.57 & $35 \%$ & 0.79 \\
PD & 0.0037 & $30 \%$ & 0.82 & 0.33 & $24 \%$ & 0.78 \\
PD $_{\mathrm{M}}$ & 0.0136 & $11 \%$ & 0.66 & 0.050 & $11 \%$ & 0.66 \\
\hline
\end{tabular}




\section{Table 4}

Best-fit values (with standard errors and percent coefficients of variation in the standard errors in parentheses) for the 10 fitted regression coefficients used in the equations for predicting the $\mathrm{P}$ enrichment ratio (PER), $\mathrm{P}$ availability index (PAI), dissolved $\mathrm{P}$ concentration from soil (DPC), $\mathrm{P}$ distribution factor for applied fertilizer $\left(\mathrm{PD}_{\mathrm{F}}\right)$, and $\mathrm{P}$ distribution factor for applied manure $\left(\mathrm{PD}_{\mathrm{M}}\right)$. Results shown for unweighted $(w=1)$ and weighted $\left(w=\mathrm{y}_{\text {pred }}{ }^{-2}\right)$ regression.

\begin{tabular}{|c|c|c|}
\hline Regression coefficient & $w=1$ & $w=\mathrm{y}_{\text {pred }}{ }^{-2}$ \\
\hline & \multicolumn{2}{|c|}{ PER (Eq. 3) } \\
\hline $\mathrm{C}_{1}$ & $7.5(0.32 ; 4.3 \%)$ & $7.3(0.29 ; 3.9 \%)$ \\
\hline \multirow[t]{2}{*}{$\mathrm{C}_{2}$} & $-0.19(0.011 ; 5.7 \%)$ & $-0.18(0.0069 ; 3.9 \%)$ \\
\hline & \multicolumn{2}{|c|}{ PAI (Eq. 7) } \\
\hline $\mathrm{C}_{3}$ & $-0.053(0.0083 ; 16 \%)$ & $-0.053(0.0087 ; 14 \%)$ \\
\hline $\mathrm{C}_{4}$ & $-0.029(0.0043 ; 15 \%)$ & $-0.030(0.0026 ; 8.4 \%)$ \\
\hline $\mathrm{C}_{5}$ & $0.0011(0.000079 ; 7.2 \%)$ & $0.0015(0.00013 ; 8.9 \%)$ \\
\hline \multirow[t]{2}{*}{$\mathrm{C}_{6}$} & $0.44(0.026 ; 5.9 \%)$ & $0.45(0.026 ; 5.8 \%)$ \\
\hline & \multicolumn{2}{|c|}{ DPC (Eq. 9) } \\
\hline \multirow[t]{2}{*}{$\mathrm{C}_{7}$} & $0.0022(0.000031 ; 1.4 \%)$ & $0.0022(0.000039 ; 1.8 \%)$ \\
\hline & \multicolumn{2}{|c|}{$\operatorname{PD}_{\mathrm{F}}(\mathrm{Eq} \cdot 11)$} \\
\hline $\mathrm{C}_{8}$ & $0.034(0.0081 ; 24 \%)$ & $0.038(0.010 ; 26 \%)$ \\
\hline \multirow[t]{2}{*}{$\mathrm{C}_{9}$} & $3.5(0.36 ; 10 \%)$ & $3.3(0.45 ; 14 \%)$ \\
\hline & \multicolumn{2}{|c|}{$\mathrm{PD}_{\mathrm{M}}(\mathrm{Eq} \cdot \mathbf{1 3})$} \\
\hline $\mathrm{C}_{10}$ & $0.26(0.0072 ; 2.8 \%)$ & $0.26(0.0070 ; 2.7 \%)$ \\
\hline
\end{tabular}




\section{Table 5}

Magnitude of the $95 \%$ confidence intervals (CI) and prediction intervals (PI) as a percentage of the model-predicted value for $\mathrm{P}$ enrichment ratio (PER), $\mathrm{P}$ availability index (PAI), dissolved $\mathrm{P}$ concentration from soil (DPC), P distribution factor for applied inorganic fertilizers (PDF), and P distribution factor for applied manures (PDM). Results are shown for unweighted $(w=1)$ and weighted $\left(w=\mathrm{y}_{\text {pred }}^{-2}\right)$ regression.

\begin{tabular}{lcccc}
\hline $\begin{array}{l}\text { Model } \\
\text { Variable }\end{array}$ & CI & PI & CI & PI \\
\hline \multicolumn{2}{c}{$\boldsymbol{w = 1}$} & \multicolumn{2}{c}{$\boldsymbol{w = \mathbf { y } _ { \text { pred } } { } ^ { - 2 }}$} \\
PER & $\pm 3.1-15 \%$ & $\pm 17-92 \%$ & $\pm 3.3-8.5 \%$ & $\pm 29 \%$ \\
PAI & $\pm 3.9-40 \%$ & $\pm 25-250 \%$ & $\pm 3.9-22 \%$ & $\pm 60-89 \%$ \\
DPC & $\pm 2.7 \%$ & $\pm 15-3400 \%$ & $\pm 6.6 \%$ & $\pm 150 \%$ \\
PDF & $\pm 6.0-37 \%$ & $\pm 25-200 \%$ & $\pm 23-57 \%$ & $\pm 100-150 \%$ \\
PD $_{M}$ & $\pm 0.010-7.6 \%$ & $\pm 23-94 \%$ & $\pm 0.013-7.3 \%$ & $\pm 45 \%$ \\
\hline
\end{tabular}




\section{References}

Anderman, E.R., Hill, M.C., 1999. A new multi-stage ground-water transport inverse method: presentation, evaluation, and implications. Water Resour. Res., 35(4): 1053-1063.

Barlund, I., Tattari, S., 2001. Ranking parameters on the basis of their contribution to model uncertainty. Ecol. Model., 142: 11-23.

Beck, M.B., 1987. Water quality modeling: a review of the analysis of uncertainty. Water Resour. Res., 23: 1393-1442.

Beven, K., Binley, A.M., 1992. The future of distributed models: model calibration and uncertainty prediction. Hydrol. Process., 6: 279-298.

Beven, K.J., 2002. Towards a coherent philosophy for modelling the environment. Proc. R. Soc. Stat., 458: 2465-2484.

Beven, K.J., 2006a. A manifesto for the equafinality thesis. J. Hydrol., 320: 18-36.

Beven, K.J., 2006b. On undermining the science? Hydrol. Process., 20: 3141-3146.

Beven, K.J., Page, T., McGechan, M., 2007. Uncertainty estimation in phosphorus models. In: Radcliffe, D.E., Cabrera, M.L. (Eds.), Modeling Phosphorus in the Environment. CRC Press, Boca Raton.

Bevington, P.R., Robinson, D.K., 1992. Data Reduction and Error Analysis for the Physical Sciences. McGraw-Hill, New York.

Boesch, D.R., Hechy, R., O'Melia, C., Schindler, D., Seitzinger, S., 2006. Eutrophication of the Swedish Seas. In: Agency, S.E.P. (Ed.), Stockholm.

Bolster, C.H., Tellinghuisen, J., 2010. On the significance of properly weighting sorption data for least squares analysis. Soil Sci. Soc. Am. J., 74(2): 670-679.

Bolster, C.H., Vadas, P.A., 2013. Sensitivity and uncertainty analyis for the annual phosphorus loss estimator model. J. Environ. Qual., 42: 1109-1118.

Bormann, H., Breuer, L., Graff, T., Huisman, J.A., Croke, B., 2009. Assessing the impact of land use change on hydrology by ensemble modelling (LUCHEM) IV: model sensitivity to data aggregation and spatial (re-)distribution. Adv. Water Resour., 32: 171-192.

Butts, M.B., Payne, J.T., Kristensen, M., Madsen, H., 2004. An evaluation of the impact of model structure on hydrological modelling uncertainty for streamflow simulation. J. Hydrol., 298: 242-266.

Dai, Z., Du, J., Zhang, X., Siu, N., Li, J., 2011. Variation of riverine material loads and environmental consequences on the Changjiang (Yangtze) estuary in recent decades (1955-2008). Environ. Sci. Technol., 45: 223-227.

Dale, V.H. et al., 2010. Hypoxia in the Northern Gulf of Mexico. Springer Series on Environmental Management. Springer Science, New York.

Dean, S., Freer, J., Beven, K., Wade, A.J., Butterfield, D., 2009. Uncertainty assessment of a process-based integrated catchment model of phosphorus. Stoch. Environ. Res. Risk Assess., 23: 991-1010.

Draper, N.R., Smith, H., 1998. Applied Regression Analysis. John Wiley \& Sons, New York.

Edwards, A.C., Daniel, T.C., Murdoch, J.F., Moore, J., P.A., 1996. Quality of runoff from four northwest Arkansas pasture field treated with organic and inorganic fertilizer. Trans. ASAE, 39: 1689-1696. 
Executive Order 13508, 2009. Draft strategy for restoring and protecting the Chesapeake Bay. Federal Leadership Committee for the Chesapeake Bay. http://executiveorder.chesapeakebay.net/file.axd?file=2010\%2f9\%2fChesapeake+EO+Ac tion+Plan+FY2011.pdf (accessed 22 February 2016).

Georgakakos, K.P., Seo, D.-J., Gupta, H., Schaake, J., Butts, M.B., 2004. Characterising streamflow simulation uncertainty through multimodel ensembles. J. Hydrol., 298(1-4): 222-241.

Gupta, H.V., Clark, M.P., Vrugt, J.A., Abramowitz, G., Ye, M., 2012. Towards a comprehensive assessment of model structural adequacy. Water Resour. Res., 48.

DOI:10:1029/2011WR011044

Haan, C.T., 2002. Statistical Methods in Hydrology. Iowa State Press, Ames, IA, 496 pp.

Harmel, R.D., Cooper, R.J., Slade, R.M., Haney, R.L., Arnold, J.G., 2006. Cumulative uncertainty in measured streamflow and water quality data for small watersheds. Trans. ASABE, 49(3): 698-701.

Harmel, R.D., Smith, D.R., King, K.W., Slade, R.M., 2009. Estimating storm discharge and water quality uncertainty: A software tool for monitoring and modeling applications. Environ. Model. Softw., 24: 832-842.

Harmel, R.D., Torbert, H.A., Haggard, B.E., Haney, R., Dozier, M., 2004. Water quality impacts of converting to a poultry litter fertilization strategy. J. Environ. Qual., 33: 2229-2242.

HELCOM, 2011. The Fifth Baltic Sea Pollution Load Compilation (PLC-5) Balt. Sea Environ. Proc. No. 128. http://helcom.fi/Lists/Publications/BSEP128.pdf (accessed 22 February 2016).

Helsel, D.R., Hirsch, R.M., 2002. Statistical Methods in Water Resources. U.S. Geological Survey Techniques in Water Resources, Book 4.

Hill, M.C., Tiedeman, C.R., 2007. Effective Groundwater Model Calibration. John Wiley and Sons, Hoboken, $455 \mathrm{pp}$.

Jakeman, A.J., Letcher, R.A., Norton, J.P., 2006. Ten interative steps in development and evaluation of environmental models. Environ. Model. Softw., 21: 602-614.

Janssen, P.H.M., Petersen, A.C., Van der Sluijs, J.P., Risbey, J.S., Ravetz, J.R., 2005. A guidance for assessing and communicating uncertainties. Water Sci. Technol., 52: 125131.

Jones, C.A., Cole, C.V., Sharpley, A.N., Williams, J.R., 1984. A simplified soil and plant phosphorus model: I. Documentation. Soil Sci. Soc. Am. J., 48: 800-805.

Kleinman, P.J.A., Sharpley, A.N., Withers, P.J.A., Bergstrom, L., Johnson, L.T., Doody, D.G., 2015. Implementing agricultural phsophorus science and management to combat eutrophication. Ambio, 44: S297-S310. DOI:10.1007/s13280-015-0631-2

Krueger, T., Quinton, J.N., Freer, J., Macleod, C.J.A., Bilotta, G.S., Brazier, R.E., Butler, P., Haygarth, P.M., 2009. Uncertainties in data and models to describe event dynamics of agricultural sediment and phosphorus transfer. J. Environ. Qual., 38: 1137-1148.

McDowell, L.L., McGregor, K.C., 1980. Nitrogen and phosphorus losses in runoff from no-till soybeans. Trans. ASAE., 23: 643-648.

McFarland, A.M.S., Hauck, L.M., 2001. Determining nutrient export coefficients and source loading uncertainty using in-stream monitoring data. J. Am. Water Resourc. Assoc., 37: 223-236.

National Research Council, 2007. Models in Environmental Regulatory Decision Making. National Academy of Sciences. 
Owens, L.B., Shipitalo, M.J., 2006. Surface and subsurface phosphorus losses from fertilized pasture systems in Ohio. J. Environ. Qual., 35: 1101-1109.

Pappenberger, F., Beven, K.J., 2006. Ignorance is bliss: Or seven reasons not to use uncertainty analysis. Water Resour. Res., 42.

Radcliffe, D.E., Cabrera, M.L., 2007. Modeling Phosphorus in the Environment. CRC Press, Boca Raton, 420 pp.

Radcliffe, D.E., Freer, J., Schoumans, O.F., 2009. Diffuse phosphorus models in the United States and Europe: Their usages, scales, and uncertainties. J. Environ. Qual., 38: 19561967.

Refsgaard, J.C., van der Sluijs, J.P., Brown, J., van der Keur, P., 2006. A framework for dealing with uncertainty due to model structure error. Adv. Water Resour., 29: 1586-1597.

Refsgaard, J.C., van der Sluijs, J.P., Hojberg, A.L., Vanrollegham, P.A., 2007. Uncertainty in the environmental modelling process - A framework and guidance. Environ. Model. Softw., 22: $1543-1556$.

Reichert, P., Borsuk, M.E., 2005. Does high forecast uncertainty preclude effective decision support? Environ. Model. Softw., 20: 991-1001.

Richardson, C.J., King, R.S., Qian, S.S., Vaithiyanathan, P., Qualls, R.G., Stow, C.A., 2007. Estimating ecological thresholds for phosphorus in the Everglades. Environ. Sci. Technol., 41: 8084-8091.

SAS Institute Inc., 2011. SAS 9.3 System Options: Reference, Second Edition. SAS Institute Inc. Cary, NC.

Seber, G.A.F., Wild, C.J., 2003. Nonlinear Regression. John Wiley \& Sons, Hoboken, NJ, 768 pp.

Sharpley, A.N., 2007. Modeling phosphorus movement from agriculture to surface waters. In: Radcliffe, D.E., Cabrera, M.L. (Eds.), Modeling Phosphorus in the Environment. CRC Press, Boca Raton, FL.

Sharpley, A.N. et al., 2015. Future agriculture and minimized phosphorus losses to waters: Research needs and direction. Ambio, 44: 163-179. DOI:10.1007/s13280-014-0612-x

Sharpley, A.N., Kleinman, P.J.A., McDowell, R.W., Gitau, M., Bryant, R.B., 2002. Modeling phosphorus transport in agricultural watersheds: processes and possibilities. J. Soil Water Conserv., 57: 425-439.

Smith, R.M.S., Wheater, H.S., 2004. Multiple objective evaluation of a simple phosphorus transfer model. Hydrol. Process., 18: 1703-1720.

Soileau, J.M., Touchton, J.T., Hajek, B.F., Yoo, K.H., 1994. Sediment, nitrogen, and phosphorus runoff with conventional and conservation tillage cotton in a small watershed. J. Soil Water Conserv., 49: 82-89.

Sorooshian, S., Gupta, V.K., 1995. Model Calibration. In: Singh, V.P. (Ed.), Computer Models of Watershed Hydrology. Water Resources Publications, Baton Rouge, pp. 23-68.

Tellinghuisen, J., Bolster, C.H., 2009. Weighting formulas for the least squares analysis of binding constant data. J. Phys. Chem. A, 113: 6151-6157.

Tellinghuisen, J., Bolster, C.H., 2010. Least-squares analysis of phosphorus soil sorption data with weighting from variance function estimation: A statistical case for the Freundlich isotherm. Environ. Sci. Technol., 44: 5029-5034.

Thoma, D.P., Gupta, S.C., Strock, J.S., Moncrief, J.F., 2005. Tillage and nutrient source effects on water quality and corn grain yield from a flat landscape. J. Environ. Qual., 34: 11021111. 
USDA-NRCS, 2013. Assessment of the Effects of Conservation Practices on Cultivated Cropland in the Lower Mississippi River Basin. In: NRCS, U. (Ed.), Washington, DC.

USEPA, 2009. Guidance on the Development, Evaluation, and Application of Environmental Models, Washington, DC.

Uusitalo, L., Lehikoinen, A., Helle, I., Myrberg, K., 2015. An overview of methods to evaluate uncertainty of deterministic models in decision support. Environ. Model. Softw., 63: 2431.

Vadas, P.A., Good, L.W., Moore Jr., P.A., Widman, N., 2009. Estimating phosphorus loss in runoff from manure and fertilizer for a phosphorus loss quantification tool. J. Environ. Qual., 38: 1645-1653.

Vadas, P.A., Kleinman, P.J.A., Sharpley, A.N., 2004. A simple method to predict dissolved phosphorus in runoff from surface-applied manures. J. Environ. Qual., 33: 749-756.

Vadas, P.A., Kleinman, P.J.A., Sharpley, A.N., Turner, B.L., 2005. Relating phosphorus to dissolved phosphorus in runoff: A single extraction coefficient for water quality modeling. J. Environ. Qual., 34: 572-580.

Vadas, P.A., Owens, L.B., Sharpley, A.N., 2008. An empirical model for dissolved phosphorus in runoff from surface-applied fertilizers. Agric. Ecosyst. Environ., 127: 59-65.

Vadas, P.A., White, M.J., 2010. Validating soil phosphorus routines in the SWAT model. Trans. ASABE, 53(5): 1469-1476.

Vecchia, A.V., Cooley, R.L., 1987. Simultaneous confidence and intervals for non-linear regression models with application to a groundwater flow model. Water Resour. Res., 22(2): 95-108.

Veith, T.L., Van Liew, M.W., Bosch, D.D., Arnold, J.G., 2010. Parameter sensitivity and uncertainty in SWAT: A comparison across five USDA-ARS watersheds. Trans. ASABE, 53(5): 1477-1486.

Voinov, A., Bousquet, F., 2010. Modelling with stakeholders. Environ. Model. Softw., 25: 12681281.

Westerman, P.W., King, L.D., Burns, J.C., Cummings, G.A., Overcash, M.R., 1987. Swine manure and lagoon effluent applied to a temperate forage mixture: II. Rainfall runoff and soil chemical properties. J. Environ. Qual., 16: 106-112.

Yen, H., Wang, X., Fontane, D.G., Harmel, R.D., Arabi, M., 2014. A framework for propogation of uncertainty contributed by parameterization, input data, model structure, and calibration/validation data in watershed modeling. Environ. Model. Softw., 54: 211-221.

Young, R.A., Holt, R.F., 1977. Winter-applied manure: Effects on annual runoff, erosion, and nutrient movement. Journal of Soil and Water Conservation, 32: 219-222.

Zhang, J., Haan, C.T., 1996. Evaluation of uncertainty in estimated flow and phosphorus loads by FHANTM. Trans. ASAE, 12(6): 663-669. 

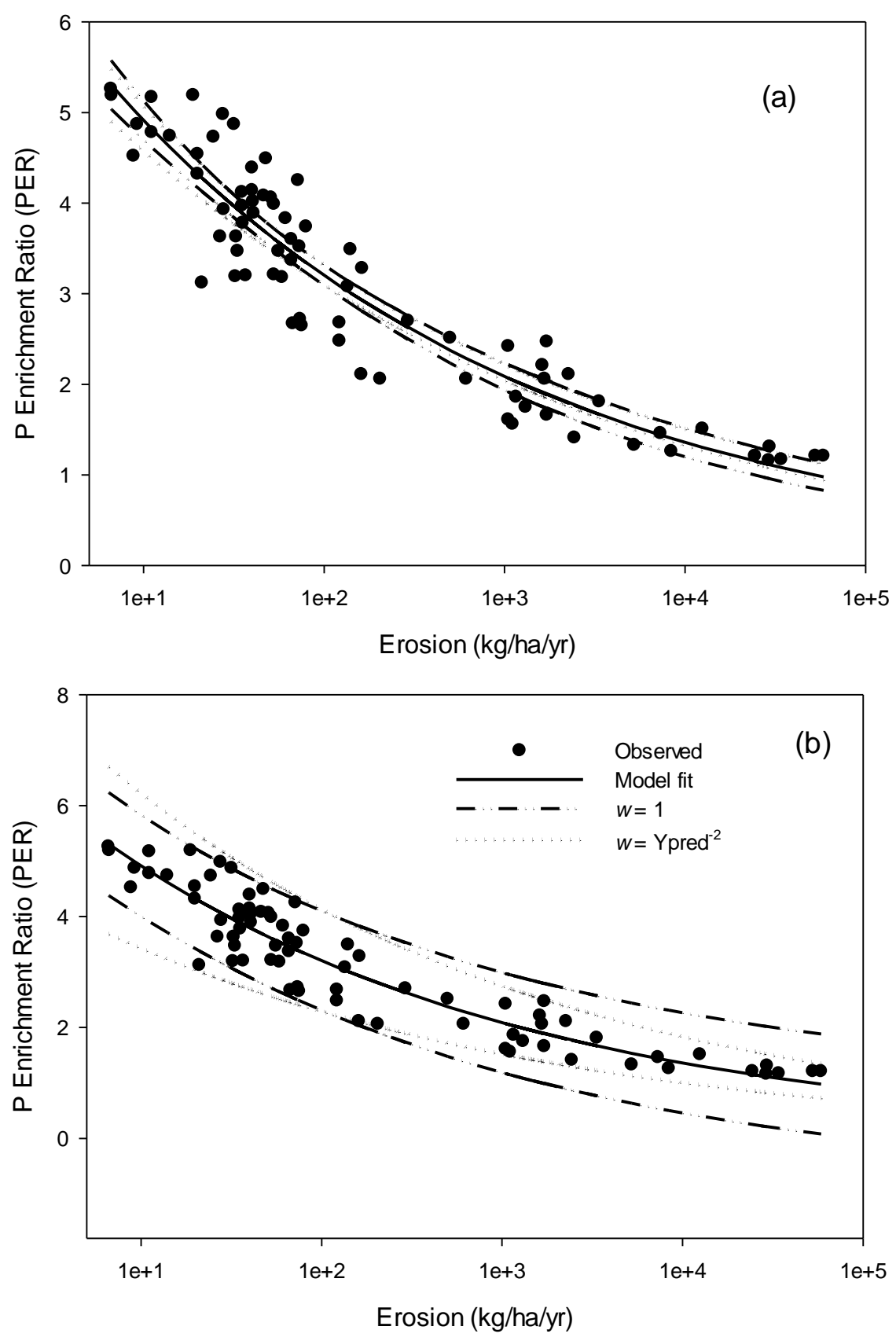

Fig. 1. Scatter plot showing relationship between observed (symbols) and fitted (solid line) values of the $\mathrm{P}$ enrichment ratio (PER) and measured annual erosion rates. Data were obtained from Sharpley (Sharpley, 2007). Also included are the $95 \%$ confidence (a) and prediction (b) intervals calculated for two error distributions: constant error $(w=1)$ and proportional error variance $\left(w=\mathrm{y}_{\text {pred }}{ }^{-2}\right)$. 

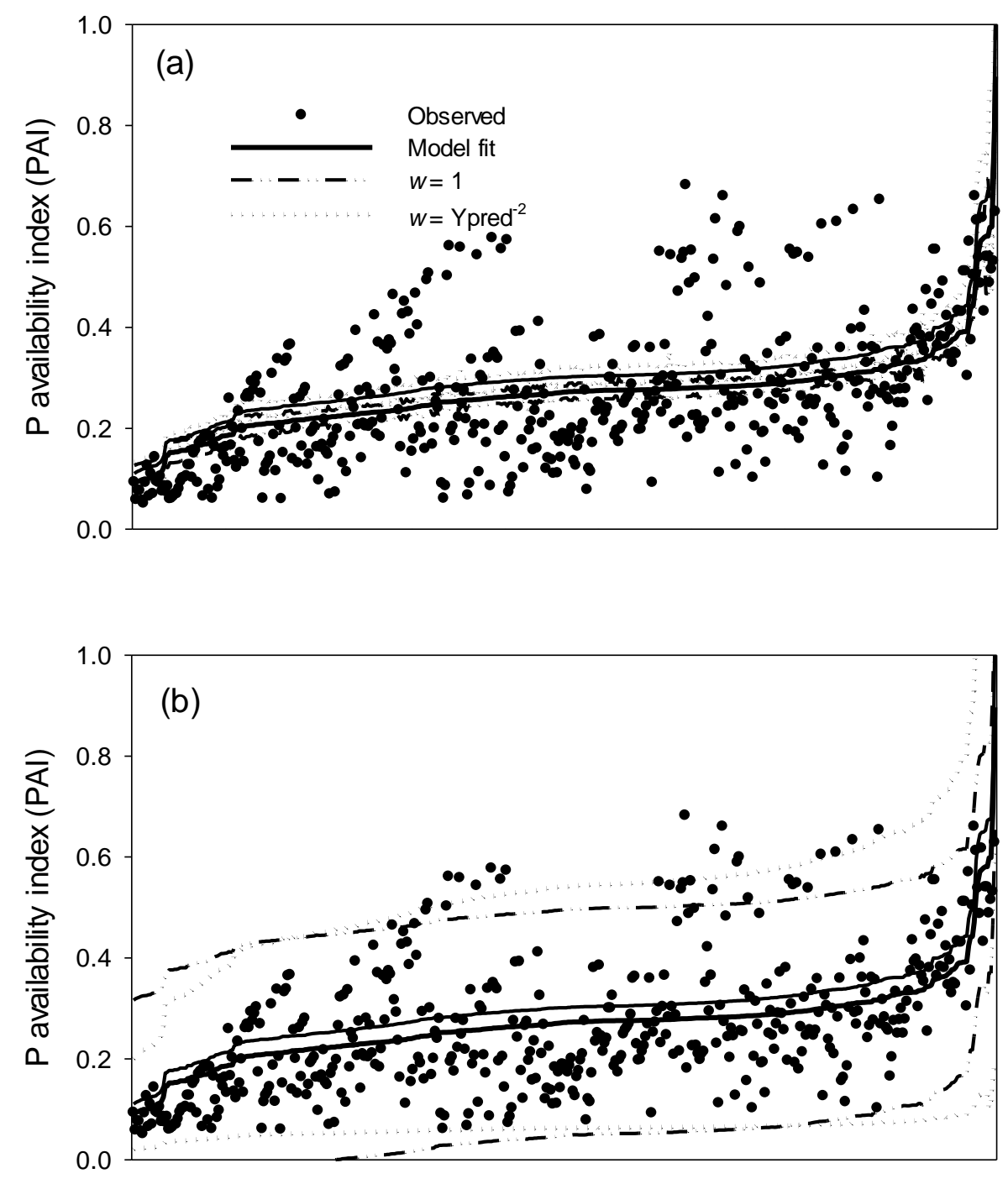

Fig. 2. Scatter plot showing observed (symbols) and fitted (solid line) values of the $P$ availability index (PAI). Data along the $\mathrm{x}$ axis are plotted in increasing order of the predicted PAI values.

Data are from Vadas and White (2010). Also included are the $95 \%$ confidence (a) and prediction (b) intervals calculated for two error distributions: constant error $(w=1)$ and proportional error variance $\left(w=\mathrm{y}_{\text {pred }}{ }^{-2}\right)$. 

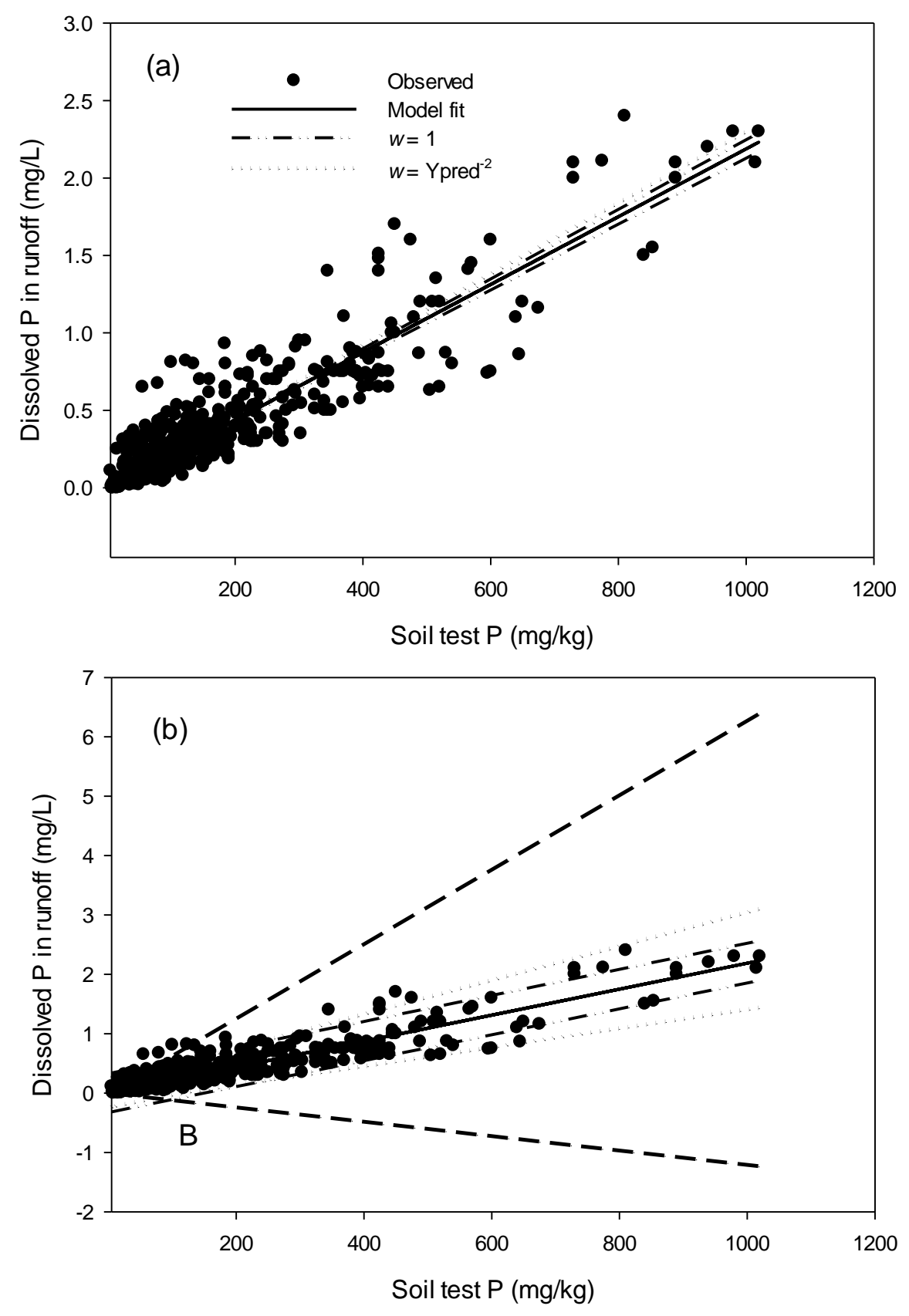

Fig. 3. Scatter plot showing relationship between observed (symbols) and fitted (solid line) values of runoff P concentration and soil test P. Data were obtained from Vadas et al. (2005). Also included are the $95 \%$ confidence (a) and prediction (b) intervals calculated for two error distributions: constant error $(w=1)$ and proportional error variance $\left(w=\mathrm{y}_{\text {pred }}{ }^{-2}\right)$. 

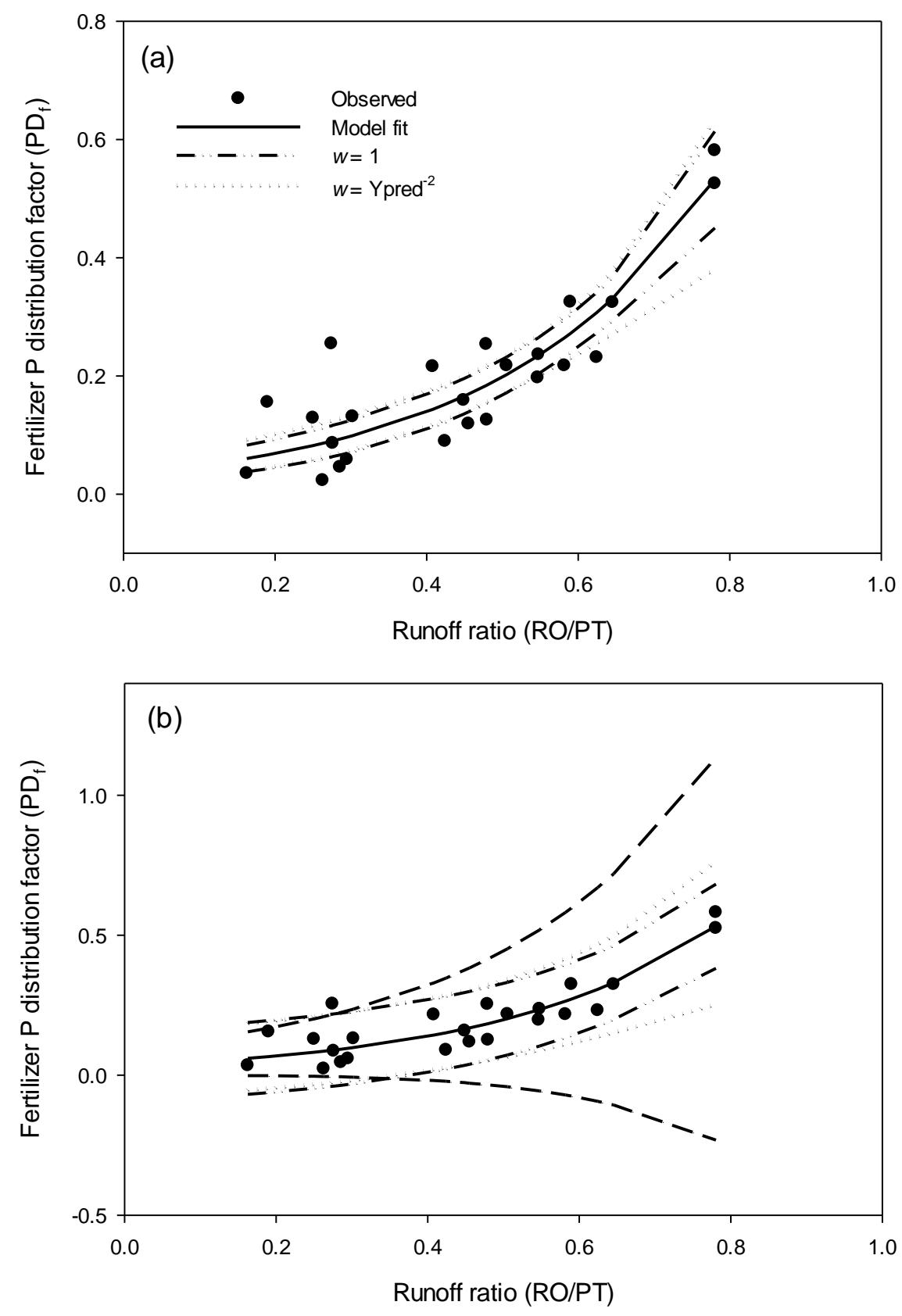

Fig. 4. Scatter plot showing relationship between observed (symbols) and fitted (solid line) values of the fertilizer $\mathrm{P}$ distribution factor $\left(\mathrm{PD}_{\mathrm{F}}\right)$ and runoff to precipitation ratio $(\mathrm{RO} / \mathrm{PT})$. Data from Vadas et al. (2008). Also included are the $95 \%$ confidence (a) and prediction (b) intervals calculated for two error distributions: constant error $(w=1)$ and proportional error variance $(w=$ $\left.\mathrm{y}_{\text {pred }}{ }^{-2}\right)$. 

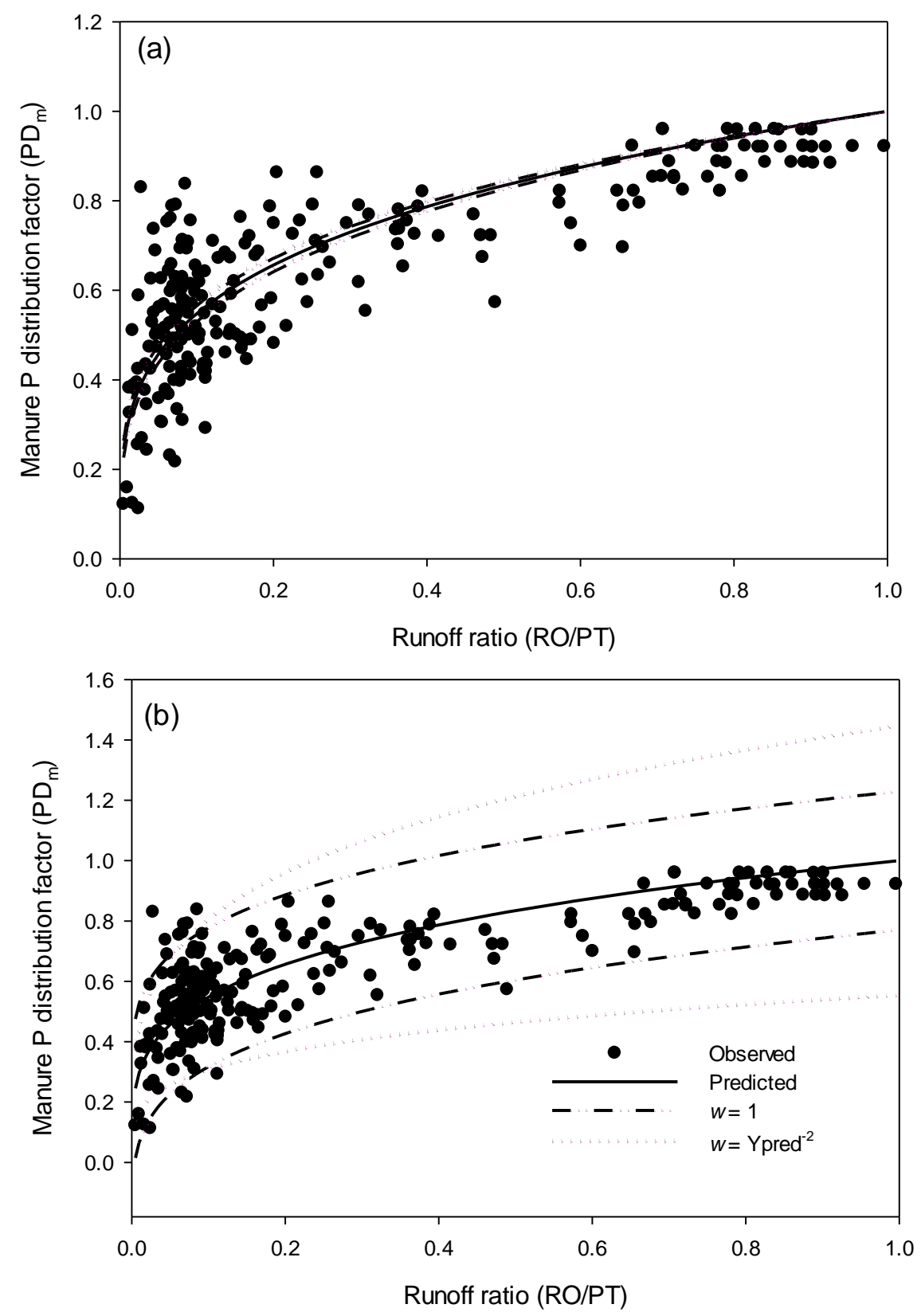

Fig. 5. Scatter plot showing relationship between observed (symbols) and fitted (solid line) values of the manure $\mathrm{P}$ distribution factor $\left(\mathrm{PD}_{\mathrm{m}}\right)$ and runoff $(\mathrm{RO})$ to precipitation $(\mathrm{PT})$ ratio. Data from Vadas et al. (2004). Also included are the $95 \%$ confidence (a) and prediction (b) intervals calculated for two error distributions: constant error $(w=1)$ and proportional error variance $(w=$ $\mathrm{y}_{\text {pred }}{ }^{-2}$ ). 

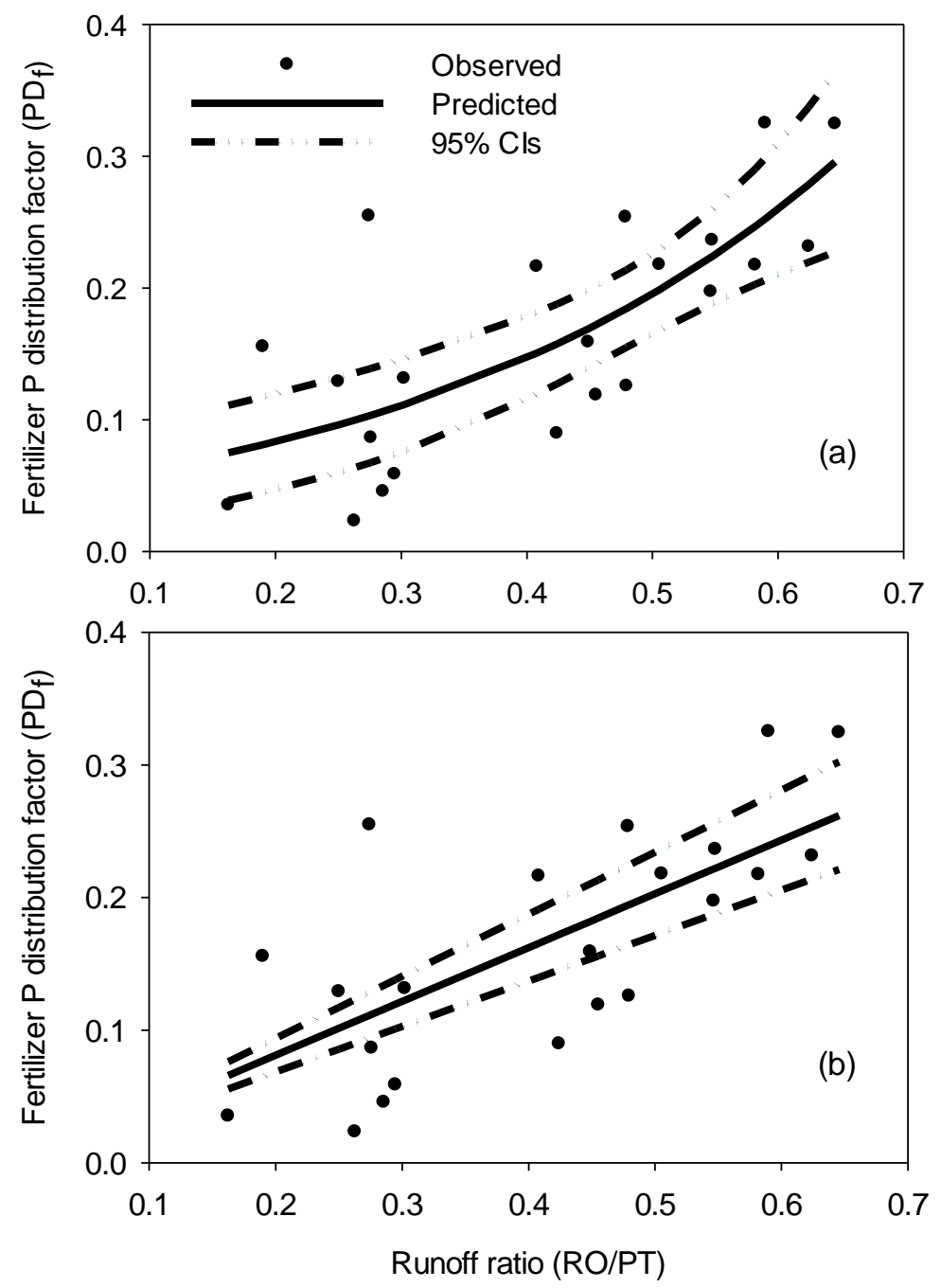

Fig. 6. Observed and fitted values along with $95 \%$ confidence intervals (CIs) for the fertilizer P distribution factor $\left(\mathrm{PD}_{\mathrm{F}}\right)$ as a function of the annual runoff to precipitation ratio (RO/PT) using a) exponential $\left(\mathrm{PD}_{\mathrm{F}}=0.047 \pm 0.016 \cdot \exp [2.8 \pm 0.62 \cdot \mathrm{RO} / \mathrm{PT}]\right)$ and $\left.\mathrm{b}\right)$ linear $\left(\mathrm{PD}_{\mathrm{F}}=0.41 \pm 0.030 \cdot\right.$ $\mathrm{RO} / \mathrm{PT}$ ) equations. The highest two values of runoff ratio from the original data set were removed $(n=22)$. Fit statistics were similar for the two equations but uncertainty was lower for the linear equation. 


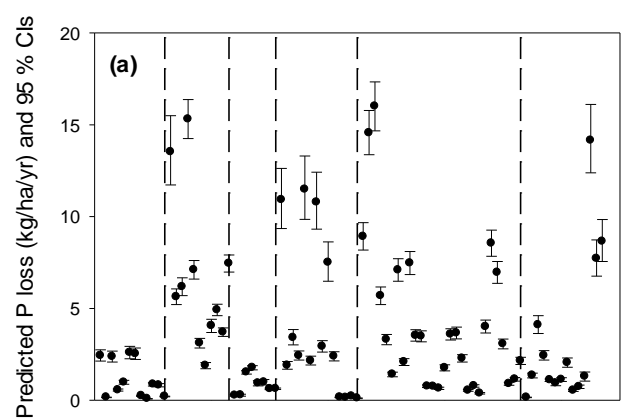

Field Groupings (FG)

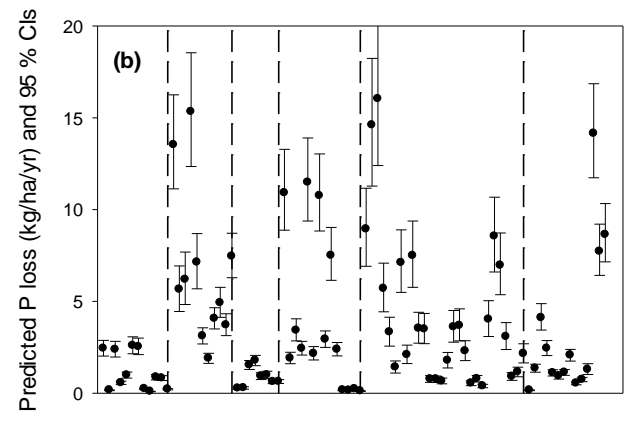

Field Groupings (FG)

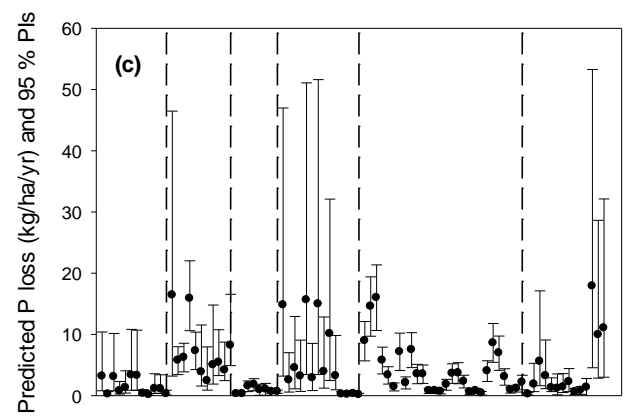

Field Groupings (FG)

Fig. 7. Predicted P loss and $95 \%$ confidence intervals (CIs) for (a) Error Treatment 4: error in the regression equations calculated from the $95 \%$ CIs and $\pm 5 \%$ error in the model input variables, (b) Error Treatment 5: error in the regression equations calculated from the $95 \%$ CIs and $\pm 15 \%$ error in the model input variables, and (c) Error Treatment 6: error in regression equations calculated from the $95 \%$ PIs. Vertical lines demarcate the following field groupings (FG): I) no P application, II) P applied as inorganic fertilizer with erosion, III) P applied as manure to fields without erosion, IV) $\mathrm{P}$ applied as manure to fields with observed erosion, V) $\mathrm{P}$ applied both as fertilizer and manure to fields without erosion, VI) P applied both as fertilizer and manure to fields with observed erosion. 


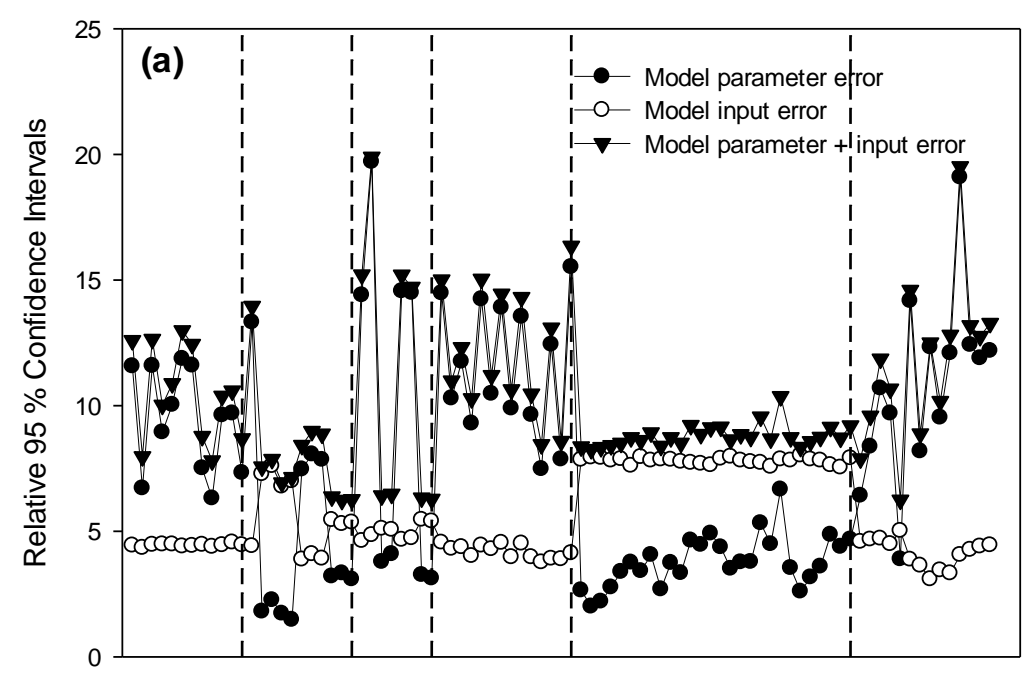

Field Groupings (FG)

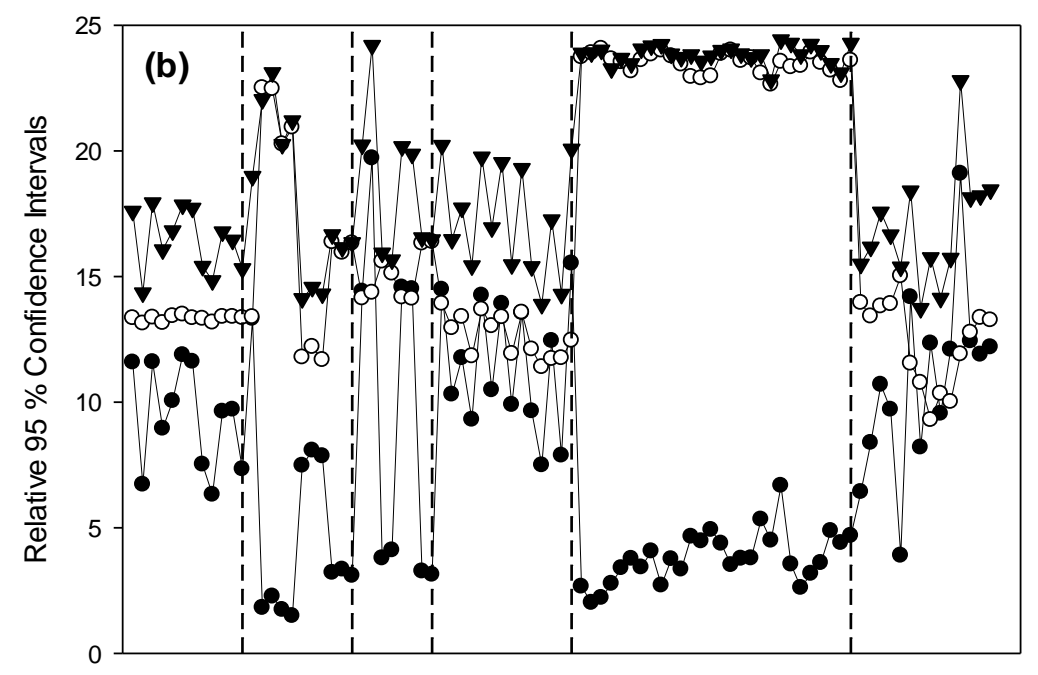

Field Groupings (FG)

Fig. 8. Relative $95 \%$ confidence intervals ( $\pm \%$ of model-predicted P loss) for model-predicted P loss accounting for error in the APLE model parameters only $(\bullet)$, in model input variables only (O ), and combined model parameter and input errors ( $\nabla$ ) for model input errors of (a) $\pm 5 \%$ and (b) $\pm 15 \%$. Vertical lines demarcate the following field groupings (FG): I) no P application, II) P applied as inorganic fertilizer with erosion, III) $\mathrm{P}$ applied as manure to fields without erosion, IV) $\mathrm{P}$ applied as manure to fields with erosion, V) $\mathrm{P}$ applied both as fertilizer and manure to fields without erosion, VI) P applied both as fertilizer and manure to fields with erosion. 